\title{
The Effect of Density Gradient Centrifugation and Magnetic-Activated Cell Sorting with the Combination of Both on Bovine Spermatozoa Kinematics, Viability and Acrosome Status
}

\author{
Khairul Osman ${ }^{1}$, Noraina Mohd Bakri ${ }^{2}$, Farah Hanan Fathihah Jaffar ${ }^{2}$, Nurul Atikah Osman ${ }^{2}$ \\ \& Siti Fatimah Ibrahim ${ }^{2}$ \\ ${ }^{1}$ Department of Forensic Sciences, Faculty of Health Sciences, Universiti Kebangsaan Malaysia, Kuala Lumpur, \\ Malaysia \\ ${ }^{2}$ Department of Physiology, Universiti Kebangsaan Malaysia Medical Centre, Kuala Lumpur, Malaysia \\ Correspondence: Siti Fatimah Ibrahim, Department of Physiology, Universiti Kebangsaan Malaysia Medical \\ Centre, Jalan Yaacob Latif, Bandar Tun Razak, 56000 Cheras, Wilayah Persekutuan, Kuala Lumpur, Malaysia. \\ Tel: 60-391-458-615. Fax: 60-326-938-717. E-mail: timi@ukm.edu.my
}

Received: October 3, 2017

Accepted: December 12, 2017

Online Published: December 31, 2017

doi:10.5539/jas.v9n13p73

URL: https://doi.org/10.5539/jas.v9n13p73

\begin{abstract}
Conventional and novel spermatozoa separation techniques have their own strength and weaknesses. Both are widely used in assisted reproductive technologies (ARTs). In this study, combinations of two separation methods against single separation methods were evaluated. Freshly ejaculated semen was collected and divided into five groups; control, density gradient centrifugation (DGC), magnetic activated cell sorting (MACS), DGC-MACS and MACS-DGC; based on the sequence of separation. Evaluation of spermatozoa kinematics, viability and acrosome status for each group were done by computer assisted semen analysis (CASA), hypo-osmotic swelling test (HOST) and chlorotetracycline (CTC) staining respectively. Results show that DGC yield the fastest spermatozoa velocity and highest percentage of viable spermatozoa fraction compared to other groups. However, they also produced a high percentage of acrosome-reacted spermatozoa. Spermatozoa isolated through DGC-MACS shows the highest percentage of non-capacitated spermatozoa. However, spermatozoa isolated through DGC-MACS yields slower spermatozoa velocity population and lower percentage of viable sperm compared to spermatozoa isolated through DGC. Isolation of spermatozoa through MACS-DGC yields slower population of spermatozoa velocity with a lower percentage of non-capacitated spermatozoa compared to spermatozoa isolated through DGC-MACS. DGC separation and its combination with MACS had yield different spermatozoa quality. This distinct characteristic is likely suitable for in vitro fertilization (IVF) and intracytoplasmic sperm injection (ICSI) procedure respectively.
\end{abstract}

Keywords: magnetic-activated cell sorting, density gradient centrifugation, spermatozoa viability, kinematics, acrosome

\section{Introduction}

Successful ART requires viable and good quality of spermatozoa (Ibrahim et al., 2008). Numerous techniques have been developed to isolate good quality spermatozoa. The evolution began from simple washing to complicated and sophisticated technique. Most of the conventional techniques produce excessive amounts of reactive oxygen species (ROS) (Ghaleno et al., 2014). ROS affects spermatozoa plasma membrane, spermatozoa motility, DNA integrity and initiate apoptosis unintentionally (Agarwal, Saleh, \& Bedaiwy, 2003).

For most infertility cases, swim up method or density gradient centrifugation (DGC) seemed to be the best conventional techniques. These techniques are able to isolate motile and morphologically normal spermatozoa efficiently (Xue et al., 2014). However, it is based on sedimentation and migration. This would limit isolation of apoptotic spermatozoa (Dirican et al., 2008). Magnetic activated cell sorting (MACS) is able to isolate non-apoptotic cells from the semen based on the expression of phosphotidylserine (PS) on the spermatozoa's cell surface (Nadalini, Tarozzi, Di Santo, \& Borini, 2014). ROS production is negligible because no mechanical force is involved (Faezah et al., 2014). 
This study compares the effect of DGC, MACS and the combination towards sperm separation. We hypothesized that combination of both techniques will produce better quality spermatozoa.

\section{Material and Methods}

\subsection{Semen Collection}

Semen collection was done at National Veterinary Biodiversity Institute. The ECP 15 bull (Charolaise and Kedah-Kelantan crossbreed) semen was freshly collected by using artificial vagina. The concentration of fresh semen was immediately determined by using Spermacue ${ }^{\mathrm{TM}}$ and evaluation of spermatozoa kinematics was observed by using computer assisted semen analysis (CASA). The semen was then divided into three groups of equal volumes. The three groups were then classified as control, DGC and MACS group. Later the spermatozoa isolated through DGC had undergone second separation through MACS. Meanwhile, the spermatozoa isolated trough MACS will undergo second separation trough DGC. The groups were designated as DGC-MACS group and MACS-DGC group based on the sequence of separation as experimental groups for combined separation method.

\subsection{Spermatozoa Separation}

\subsubsection{Density Gradient Centrifugation Separation (Isolate ${ }^{\circledR}$ Kit)}

Isolate ${ }^{\circledR}$ Kit (Irvine Scientific, USA) was used for DGC. It consisted of two media which are the lower and upper layers. Both media were pipetted into an eppendorf tube according to the order of the layer before $250 \mu \mathrm{L}$ of fresh semen was transferred onto the media. The semen and media were then centrifuged at $300 \mathrm{~g}$ for 20 minutes. The concentration of the remaining pellet was determined through the use of Spermacue ${ }^{\mathrm{TM}}$. Later, the pellet was diluted in Bio-excell extender to a final concentration of $25 \times 10^{6} \mathrm{sperm} / \mathrm{ml}$ before the quality of the sample was evaluated.

\subsubsection{Magnetic-Activated Cell Sorting (MACS)}

Fresh semen was diluted to a final concentration of $10^{6}$ to $10^{7}$ cells. For a single separation, $250 \mu$ l of diluted semen was used. The procedure was carried out according to manufacturer's instruction provided in the kit (Miltenyi Biotech, Germany). Briefly, $250 \mu \mathrm{l}$ of semen was centrifuged for 10 minutes at $300 \mathrm{~g}$. The pellet was resuspended with $80 \mu \mathrm{l}$ of $1 \times$ buffer and $20 \mu \mathrm{l}$ annexin V microbeads. The mixture was incubated at $6{ }^{\circ} \mathrm{C}$ to 12 ${ }^{\circ} \mathrm{C}$ for 15 minutes in the dark. After incubation, the sample was washed and resuspended with $500 \mu 1$ of $1 \times$ binding buffer (MiniMacs kit, Miltenyi Biotec, GmbH, Germany). Before the sample was placed into the MACS column, the separation column was placed on a magnet stand and flushed with $500 \mu \mathrm{l}$ of $1 \times$ binding buffer (MiniMacs kit, Miltenyi Biotec, GmbH, Germany). Such that, the annexin V microbead labelled spermatozoa were retained in the separation column. The annexin V microbead negative fraction represent the fraction with intact membranes which could passed through the column and were collected. The concentration of ANMB-negative sample was determined and the quality of the sample evaluated prior to subsequent analysis.

\subsection{Determination of Spermatozoa Viability through Modified Hypo-Osmotic Swelling Test (HOST)}

HOST was carried out according to the modified method by Osman et al. (2012). HOST solution (190 mOsm/L) was prepared by dissolving $0.735 \mathrm{~g}$ trisodium citrate dihydrate and $1.351 \mathrm{~g} \mathrm{D}(-)$ Fructose in $100 \mathrm{ml} \mathrm{dH}_{2} \mathrm{O}$. This solution was then added to the semen sample with a ratio of 10:1. The mixture was incubated for 45 minutes at $37^{\circ} \mathrm{C}$. Approximately $10 \mu \mathrm{l}$ of mixture was smeared on to a clean glass slide. The smear was air dried. Staining procedure was carried out according to the method of Lee et al. (2009) by using Diff-Quik ${ }^{\circledR}$ stain (IVD Company, Switzerland). The stained slides were observed under a light microscope under $100 \times$ magnification. Hundred cells were counted for each slide and each sample was duplicated.

\subsection{Determination of Spermatozoa Acrosome Reaction by Using Cholorotetracylcine (CTC) Staining}

The fresh or processed semen sample was centrifuged at $300 \times \mathrm{g}$ for 5 minutes at $4{ }^{\circ} \mathrm{C}$. Supernatant was removed and $150 \mu \mathrm{l}$ of pellet was transferred into a tube. The pellet was incubated at $37^{\circ} \mathrm{C}$ with $3 \mu \mathrm{l}$ of propidium iodide (PI) $(0.5 \mu \mathrm{g} / \mathrm{ml})$ and $3 \mu \mathrm{l}$ of $40 \mu \mathrm{g} / \mathrm{ml}$ Hoechst 342 . After 15 minutes of incubation at $37^{\circ} \mathrm{C}$, CTC solution was added to a drop of sample on the slide at a ratio of 1:1. A drop of $12.5 \mathrm{M}$ paraformaldehyde and a drop of $0.22 \mathrm{M}$ $\mathrm{DABCO}$ was added to the sample droplet on the slide. Slide was then immediately observed using a fluorescent microscope with excitation was set at $365 \mathrm{~nm}$ and $435 \mathrm{~nm}$ for emission. Hundred cells were counted for each slide.

\subsection{Statistical Analysis}

One-way analysis of variance (One Way ANOVA) was used to determine the effect of multiple separation methods on spermatozoa velocity and progression. Kruskal-Wallis test were done for viability and acrosome 
status of spermatozoa. Results were reported as mean \pm SEM. Differences were considered significant when $\mathrm{p}<$ 0.05 .

\section{Results}

Kinematics of spermatozoa was reported as velocity and progression. Result had indicated that there were significant differences between groups for velocity (Table 1). MACS, DGC-MACS and MACS-DGC showed a significant difference with control group and DGC group for velocity average path (VAP). However, there was no significant difference between control and DGC group for VAP. The different of velocity straight line (VSL) value for DGC, MACS, DGC-MACS and MACS-DGC are significant with control group. There are significant differences for VSL value between MACS, DGC-MACS and MACS-DGC in comparison with and DGC. The velocity curvilinear (VCL) value decreased significantly between control group and MACS, DGC-MACS and MACS-DGC. There was a slightly increase of VCL value for DGC compared to control group but the differences were not significant. There are significant differences between in VCL value between MACS, DGC-MACS and MACS-DGC in comparison with DGC. However, for progression of spermatozoa, there were no significant different between all group (Table 2).

Table 1. The effect of single spermatozoa separation procedures and combined spermatozoa separation procedures on the sperm velocity

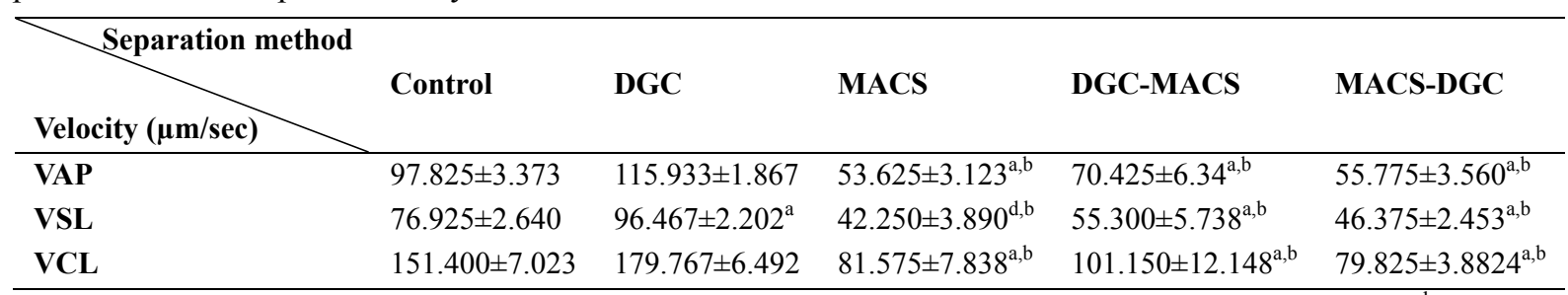

Note. Data are expressed as mean \pm SEM. $\left({ }^{a}\right)$ indicate significant difference compared to control. $\left({ }^{b}\right)$ indicate significant difference with DGC. $\left({ }^{\mathrm{d}}\right)$ indicate significant difference compared to DGC-MACS. The differences were considered significant when $\mathrm{p}<0.05$.

Table 2. The effect of single spermatozoa separation procedures and combined spermatozoa separation procedures on the sperm progression

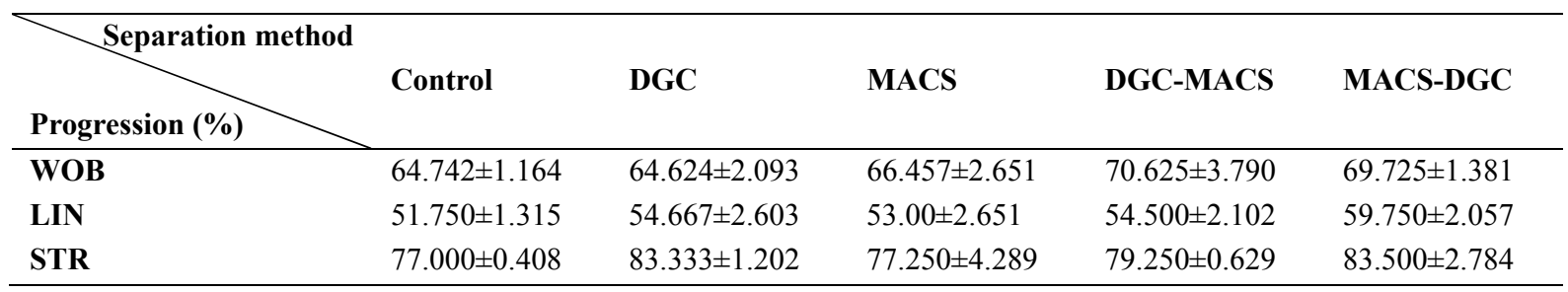

Note. Data are expressed as mean \pm SEM.

The percentage of viable sperm for each group is shown in Table 3. There was a significant difference between DGC-MACS group and DGC group.

Table 3. The effect of combined spermatozoa separation on percentage of viable spermatozoa

\begin{tabular}{ll}
\hline Separation method & Spermatozoa Viability (\%) \\
\hline Control & $60.25 \pm 5.618$ \\
DGC & $67 \pm 5.845$ \\
MACS & $32 \pm 5.845$ \\
DGC-MACS & $25.75 \pm 5.721^{\mathrm{a}}$ \\
MACS-DGC & $51.25 \pm 14.868$ \\
\hline
\end{tabular}

Note. Data are expressed as mean \pm SEM. $\left({ }^{a}\right)$ indicates significant difference compared to control group where $\mathrm{p}>$ 0.05 . Hundred cells counted and each sample was duplicated. 
Table 4 shows the acrosome status for each group. Non-capacitated spermatozoa showed significant differences between control, MACS, DGC-MACS and MACS-DGC with DGC group. The difference of non-capacitated spermatozoa was also significant between DGC-MACS group and MACS-DGC. Capacitated spermatozoa showed no significant difference for any group. However, acrosome reacted spermatozoa are significantly higher in DGC group compared to other groups.

Table 4. The effect of combined sperm separation procedures on the status of spermatozoa acrosome

\begin{tabular}{llllll}
\hline & & & & \\
& Coparation method & DGC & MACS & DGC-MACS & MACS-DGC \\
Acrosome Status & & & & & \\
\hline Non-capacitated & $82.75 \pm 4.516$ & $37.00 \pm 7.382^{\mathrm{a}}$ & $79.25 \pm 2.750^{\mathrm{b}}$ & $91.75 \pm 2.689^{\mathrm{b}}$ & $69.25 \pm 2.287^{\mathrm{b}}$ \\
Capacitated & $8.50 \pm 3.428$ & $8.00 \pm 2.677$ & $8.00 \pm 3.189$ & $1.25 \pm 0.629$ & $7.50 \pm 2.754$ \\
Acrosome Reacted & $8.50 \pm 2.398$ & $55.00 \pm 9.958^{\mathrm{a}}$ & $12.75 \pm 0.629^{\mathrm{d}}$ & $7.00 \pm 2.517^{\mathrm{d}}$ & $23.25 \pm 2.363^{\mathrm{d}}$ \\
\hline
\end{tabular}

Note. Data are expressed as mean \pm SEM. $\left({ }^{a}\right)$ indicates significant difference with control group. $\left({ }^{b}\right)$ indicates significant difference with DGC group. $\left({ }^{\mathrm{d}}\right)$ indicates significant difference with DGC-MACS.

\section{Discussion}

This study has found out that DGC isolated spermatozoa has the highest value of VAP, VSL and VCL. It also increased the velocity of fresh spermatozoa. Whereby combination methods gave no significant difference for velocity. This suggested that velocity is not affected by the combination of either method.

Fresh ejaculated semen contains small population of hyperactive spermatozoa prior to isolation (Mircu et al., 2008). Hyperactivation occurs in the presence of calcium ions or elevated ROS. Our data show that separation methods used did not produce hyperactivated sperm because VCL and average values of the ratio VSL/VCL (LIN) values were not decreased. This finding suggested that ROS level is not elevated and no additional calcium ion were added in any of the separation procedures listed above. Previous study stated fertilizing capacity of spermatozoa depends on its hyperactivity and ability to swim faster and straighter. This is indicated by higher values of VSL and LIN (Rodríguez-Miranda et al., 2008). DGC produces higher VSL, thus it might increase the capability to fertilize during ARTs. Our study also confirmed that the selection method has minimal effect on hyperactivity of fresh isolated sperm.

According to Said et al. (2008) combination of DGC followed by MACS yields a clean sperm population characterized by higher motility, viability and morphology. However, our research shows that combination of DGC followed by MACS significantly reduced the sperm viability. The discrepancy might be due to sample used in this study, bull semen compared to human in previous study which is supported by da Silva, Pinto, Young and Cole (2010). They suggested that not all species are suitable for MACS separation method. In our knowledge, most of the research for MACS separation or the combination of DGC and MACS used human samples (de Vantéry Arrighi, Lucas, Chardonnens, \& De Agostini, 2009; Gil, Shalom, Sivira, Carreras, \& Checa, 2013; Martin et al., 2017; Romany et al., 2017).

DGC has been proven to effectively remove nonviable spermatozoa. Indirectly, it increases viable spermatozoa after MACS separation. This is supported by Ollero et al. (2001) which suggested that DGC can separate mature viable spermatozoa from seminal plasma and other extraneous constituents of the seminal fluid. The presence of reacted acrosome could be due to the inability of DGC to full scrub the oocyte media from ROS and thus still creating reactive acrosome spermatozoa (Bormann, Alagretti, Motta, Serafini, \& Smith, 2010). ROS is proven to cause spermatozoa capacitation, hyperactivation, acrosome reaction, and oocyte fusion (de Lamirande \& Cagnon, 1993). DGC has also been known to be unable to eliminate spermatozoa with reacted acrosomes. This might also explain why the velocity of the isolated spermatozoa is increased compared to other groups (Franken, Bastiaan, \& Oehninger, 2000). On the other hand, MACS seemed to produce spermatozoa with the lowest quantity of acrosome reacted spermatozoa. This is not surprising as MACS separation is based on the principle of separating apoptotic and non-apoptotic spermatozoa based on the externalisation of phosphatidilserine (PS) on the outer leaflet of spermatozoa (Said, Mahfouz, Kuznyetsova, \& Del Valle, 2015).

As a conclusion, DGC single separation and the combination of DGC and MACS isolated good quality spermatozoa. In theory, the isolated sperm population is suitable to fertilize the oocyte as the acrosome of the 
resulting population has been reacted. On the other hand, combination of DGC and MACS produce non-capacitated spermatozoa which in theory is suitable for ICSI.

\section{References}

Agarwal, A., Saleh, R. A., \& Bedaiwy, M. A. (2003). Role of reactive oxygen species in the pathophysiology of human reproduction. Fertility and Sterility, 79(4), 829-843. https://doi.org/10.1016/S0015-0282(02)04948-8

Bormann, C. L., Alagretti, J. R., Motta, E. L. A., Serafini, P., \& Smith, G. D. (2010). Preparation and selection of sperm for IVF and ICSI. Reproductive Endocrinology and Infertility, 579-590. https://oi.org/10.1007/ 978-1-4419-1436-1_38

da Silva, M. A. C., Pinto, C., Young, J., \& Cole, K. (2010). 8 the use of annexin v magnetic-activated cell sorting to separate apoptotic sperm from the ejaculate of stallions. Reproduction, Fertility and Development, 23(1), 110-111. https://doi.org/10.1071/RDv23n1Ab8

de Lamirande, E., \& Cagnon, C. (1993). Human sperm hyperactivation and capacitation as parts of an oxidative process. Free Radical Biology and Medicine, 14(2),157-166. https://doi.org/10.1016/0891-5849(93) 90006-G

de Vantéry Arrighi, C., Lucas, H., Chardonnens, D., \& De Agostini, A. (2009). Removal of spermatozoa with externalized phosphatidylserine from sperm preparation in human assisted medical procreation: Effects on viability, motility and mitochondrial membrane potential. Reproductive Biology and Endocrinology, 7(1), 1-12. https://doi.org/10.1186/1477-7827-7-1

Dirican, E. K., Özgün, O. D., Akarsu, S., Akın, K. O., Ercan, Ö., Uğurlu, M., ... Ünsal, A. (2008). Clinical outcome of magnetic activated cell sorting of non-apoptotic spermatozoa before density gradient centrifugation for assisted reproduction. Journal of Assisted Reproduction And Genetics, 25(8), 375-381. https://doi.org/10.1007/s10815-008-9250-1

Faezah, S. S., Zuraina, F. M., Farah, J. H., Khairul, O., Hilwani, N. I., Iswadi, M. I., ... Fatimah, S. I. (2014). The effect of magentic separation on cryopreserved bovine spermatozoa motility, viability and cryo-capacitation status. Zygote, 22(3), 278-86. https://doi.org/10.1017/S0967199412000597

Franken, D. R., Bastiaan, H. S., \& Oehninger, S. C. (2000). Physiology: Physiological induction of the acrosome reaction in human sperm: Validation of a microassay using minimal volumes of solubilized, homologous zona pellucida. Journal of Assisted Reproduction And Genetics, 17(7), 156-161. https://doi.org/10.1023/ A:1009418222397

Ghaleno, L. R., Valojerdi, M. R., Janzamin, E., Chehrazi, M., Sharbatoghli, M., \& Yazdi, R. S. (2014). Evaluation of conventional semen parameters, intracellular reactive oxygen species, DNA fragmentation and dysfunction of mitochondrial membrane potential after semen preparation techniques: A flow cytometric study. Archives of Gynecology and Obstetrics, 289(1),173-80. https://doi.org/10.1007/s00404013-2946-1

Gil, M., Shalom, V. S., Sivira, Y. M., Carreras, R., \& Checa, M. A. (2013). Sperm selection using magnetic activated cell sorting (MACS) in assisted reproduction: A systematic review and meta-analysis. Journal of Assissted Reproduction and Genetics, 30(4), 479-485. https://doi.org/10.1007/s10815-013-9962-8

Ibrahim, S. F., Osman, K., Das, S., Othman, A. M., Majid, N. A., \& Rahman, M. P. A. (2008). A study of the antioxidant effect of alpha lipoic acids on sperm quality. Clinics, 63(4), 545-550. https://doi.org/10.1590/ S1807-59322008000400022

Lee, H. L., Kim, S. H., Ji, D. B., \& Kim, Y. J. (2009). A comparative study of Sephadex, glass wool and Percoll separation techniques on sperm quality and IVF results for cryopreserved bovine semen. Journal of Veterinary Science, 10(3), 249. https://doi.org/10.4142/jvs.2009.10.3.249

Martin, P. S., Silva, M. D., Martin, F. S., Martinez, M. G., Johnston, S. D., \& Gosalvez, J. (2017). Magnetic Cell sorting of semen containing spermatozoa with high DNA fragmentation in ICSI cycles decreses miscarriage rate. Reproductive BioMedicine Online, 34(5), 506-512. https://doi.org/10.1016/j.rbmo.2017.01.015

Mircu, C., Cernescu, H., Igna, V., Knop, R., Frunza, I., Ardelean, V., ... Korodi, G. (2008). Boar semen evaluation using CASA and its relation to fertility. Lucrvri Stintifice Medicină Veterinară, 41(119), 203-212.

Nadalini, M., Tarozzi, N., Di Santo, M., \& Borini, A. (2014). Annexin V magnetic-activated cell sorting versus swim-up for the selection of human sperm in ART: Is the new approach better then the traditional one? 
Journal of Assissted Reproduction and Genetics, 31(8), 1045-1051. https://doi.org/10.1007/s10815014-0267-3

Ollero, M., Gil-Guzman, E., Lopez, M. C., Sharma, R. K., Agarwal, A., Larson, K., ... Alvarez, J. G. (2001). Characterization of subsets of human spermatozoa at different stages of maturation: Implications in the diagnosis and treatment of male infertility. Human Reproduction, 16(9), 1912-1921. https://doi.org/10.1093/ humrep/16.9.1912

Osman, K., Nang, C. F., Ibrahim, S. F., Budin, S. B., Jaffar, F. H. F., \& Wahab, N. (2012). Albumin improved spermatozoa quality and dna integrity for freezing-free preservation. International Journal of Biological \& Medical Research, 3(2), 1670-1679.

Rodríguez-Miranda, E., Buffone, M. G., Edwards, S. E., Ord, T. S., Lin, K., Sammel, M. D., ...Williams, C. J. (2008). Extracellular adenosine 5 '-triphosphate alters motility and improves the fertilizing capability of mouse sperm. Biology of Reproduction, 79(1), 164-171. https://doi.org/10.1095/biolreprod.107.065565

Romany, L., Garrido, N., Cobo, A., Ruiz, B. A., Serra, V., \& Meseguer, M. (2017). Obstetric and perinatal outcome of babies born from sperm selected by MACS from a randomized controlled trial. Journal of Assisted Reproduction and Genetics, 34(2), 201-207. https://doi.org/10.1007/s10815-016-0838-6

Said, T. M., Agarwal, A., Zborowski, M., Grunewald, S., Glander, H. J., \& Paasch, U. (2008). Utility of magnetic cell separation as a molecular sperm preparation technique. Journal of Andrology, 29(2),134. https://doi.org/ 10.2164/jandrol.107.003632

Said, T., Mahfouz, R. Z., Kuznyetsova, I., \& Del Valle, A. P. (2015). Non-apoptotic sperm selection. In A. Agarwal, Jr. E. Borges, \& A. Setti (Eds.), Non-Invasive Sperm Selection for In Vitro Fertilization. Springer, New York, NY. https://doi.org/10.1007/978-1-4939-1411-1_7

Xue, X., Wang, W. S., Shi, J. Z., Zhang, S. L., Zhao, W. Q., Shi, W. H., ... Qin, Z. (2014). Efficacy of swim-up versus density gradient centrifugation in improving sperm deformity rate and DNA fragmentation index in semen samples from teratozoospermic patients. Journal of Assisted Reproduction and Genetics, 31(9), 1161-1166. https://doi.org/10.1007/s10815-014-0287-z

\section{Copyrights}

Copyright for this article is retained by the author(s), with first publication rights granted to the journal.

This is an open-access article distributed under the terms and conditions of the Creative Commons Attribution license (http://creativecommons.org/licenses/by/4.0/). 